\title{
Editorial: Getting published: one way to renew one's practice
}

\author{
J. G. Maree \\ University of Pretoria \\ kobus.maree@up.ac.za
}

\section{"The doctor treats the patient while time heals the disease." (Voltaire)}

In this editorial, I first consider why psychologists need to renew their practice regularly and then relate how I recently applied this principle in my own career. I give reasons for my 'paradigm shift' and enquire whether we as psychologists are prepared to accept the challenge to renew our practice on a regular basis. I then discuss the contributions in this special issue consecutively under the headings listed in the table of contents. The editorial ends with a request to readers.

\section{The need to keep abreast of change}

I believe that all theories have varying degrees of value (validity) and that no single theory should be accorded primacy. I further believe all theories have two broad functions. Firstly, they help us explain how people make choices and understand the differences in people's choices, decisions and behaviour. Allport (1937) said many years ago that people react differently to similar psycho-social stress and/or anxiety-provoking situations and stimuli — "the same fire that melts the butter, hardens the egg" (p.102). It is our task as psychologists to ascertain why this should be the case; why some people achieve in life while others (in similar situations) do not; why some people become depressed after a major setback and remain depressed while others (in similar situations) 'recover' within a relatively short period of time; why one therapeutic strategy works 'better' with certain clients than others. Secondly, theories help us to be useful to our clients, which is the ultimate aim of all theories and interventions. Here, Phares' observation (Phares, 1992) comes to mind:

$A$ rigid and blind adherence to a theory can reduce one's effectiveness as a clinician... When a better [theory] comes along, one must have the willingness and capacity to adopt it. Ultimate allegiance should be, not to a theory, but to the very best ways of describing clients and intervening on their behalf (p. 64).

Since our training and commitment to certain theoretical approaches have a major influence on how we deal with clients, we need to be open to change. Regardless of our theoretical stance, we should never be irrevocably committed to a particular theory or theoretical approach but rather to the ideal of rendering a service that is in our clients' best interests (Phares, 1992). This is not a simple task, especially in a population as diverse as South Africa's. Indeed, different weights may have to be allocated to different aspects of certain theories if these theories are to become more acceptable to all population groups (Fouad \& Bingham, in Stead \& Watson, 1999).

The realm of theory is dynamic and shaped by numerous factors, and its contours change continuously and rapidly. To facilitate adaptive behaviour by our clients, we have ourselves to become life-long learners and to share our insights with others irrespective of whether we are academics, academics who have private practices, or practitioners with little interest in theoretical matters.

\section{Changing one's theoretical and practical viewpoint: an example}

In a recent article (Maree, 2012, in press), I advocated a shift in emphasis from advising clients on what is most suitable and 'right' for them towards encouraging them to reflect on their narratives under the guidance of a skilled (career) counsellor. I did so because I believe it has become crucial to develop a deeper understanding of what can be done to help millions of young people, especially those who currently do not have access to sought-after fields of study and training institutions. I believe it is also essential to design a strategy to enable young people to script their own life stories, explore personal meanings and deal with the many problems involving meaning (self-construction 
as opposed to self-actualisation (Savickas, 2011). The aim should be to promote personal agency by viewing clients as agents in their personal development and emphasising their emotions and passions (Savickas, 2007; 2011a; 2011b). The approach (a meta-reflective paradigm) I am advocating should be useful in (career) counselling contexts and should provide career counsellors with a strategy to help clients not only 'choose' appropriate careers but also fit these careers into their lives as they attempt to design and live successful lives. I believe that such a narrational approach to career counselling will help transcend many of the weaknesses associated with traditional approaches to career counselling.

\section{Why I changed my own perspective}

To understand the thinking behind my changed perspective, I invite readers to visit the book review section where they will find a review of Mark Savickas' latest book, Career counselling (Savickas, 2011a). The book surveys developments in the career counselling field, focusing on career construction counselling and the notion of life design. It serves as a fitting curtain call to Savickas' 1993 article (Savickas, 1993), which fundamentally changed the way in which career counselling was perceived up to that stage. Already a classic in the field of career counselling, the book elaborates on the ideas put forward in the 1993 article and successive publications, covers the most recent developments and trends in the field, maps the way forward and constitutes a benchmark for all career counselling stakeholders. Savickas has consistently maintained that the advent of postmodernity prompted fundamental changes in the practice and theory of psychology (including career counselling). He has also consistently maintained that theory follows practice and that changes in the social organisation of work have necessitated a changed response from career counselling theoreticians and practitioners. The shifts that have taken place in career counselling since its formal inception some 120 years ago with the work of Frank Parsons were inevitable. Fundamental changes in the world of work have given impetus to the emergence of new careers requiring new skills and attitudes, and theoreticians and practitioners alike have no choice but to keep abreast of these developments to ensure that career counselling practice remains relevant in postmodern society (Savickas 2006a; 2006b). Career counsellors are therefore constrained to revisit their theory and practice continually in order to update their research paradigms and thus remain relevant and useful in the face of numerous and escalating changes.

The need to renew one's practice on a regular basis: how ready are we for change? The following question needs to be asked: Are South African academics, researchers and practitioners willing to heed Savickas' (2011a) important call that we should stay abreast of these developments to ensure that career counselling practice remains relevant in postmodern society? The indications, I fear, suggest a negative answer. The presentation of continuing professional development (CPD) workshops over many years has led me to believe that most practising psychologists are not keen to 'conduct research' or to publish the results of their research (if any) or to report on noteworthy findings from their private practice. This despite Holland's (1996) recommendation that all practitioners should engage in research-related activities in order to renew their practice. This could include conducting simple surveys to gauge the popularity and effectiveness of, and need for, existing services. Practitioners should also determine whether they wish to render only one service or a variety of services and whether their practice is keeping up with the times. Practitioners working alone should consider setting up partnerships with other practitioners who provide group treatments and publish the results of such treatments. Academics should be encouraged to study a wide variety of theoretical frameworks, liaise with practitioners to ascertain what is happening 'on the ground', combine ideas from different theoretical approaches in an attempt to find new explanations for human behaviour (connect the dots) and publish their findings. Most importantly: practitioners should determine the viability of their strategies and approaches in group contexts as conducting qualitative assessments 
in group and disadvantaged contexts remains a particular challenge (Maree \& Molepo, 2007). Academics, researchers and practitioners should accordingly network, conduct research and report on their findings in scholarly journals and at conferences.

\section{The current special issue: theory meeting practice}

Against this background, the current special issue of the SAJP could not have appeared at a more opportune time. In this issue, readers will encounter an array of contributions ranging from a contribution by a world-renowned scholar in the field of hypnosis (Kluft, 2012) to contributions by academics employed by universities and practitioners in private practice who do not publish regularly. What the authors all have in common is their desire to share their research findings with the rest of the scholarly and private practice community - borne out by a request of the South African Society for Clinical Hypnosis four years ago for a special issue on hypnosis.

I will now briefly discuss each of the contributions in this special issue consecutively, under the headings listed in the table of contents.

\section{Hypnotherapy in the 21st century}

A strong, positive correlation exists between hypnosis and the successful treatment of multifaceted chronic dissociative disorders. In the leading article in this section, Hypnosis in the treatment of Dissociative Identity Disorder and Allied States: an overview and case study, Richard Kluft (2012) reveals that hypnosis played a key role in the first successful treatment of what is today known as dissociative identity disorder (DID). Kluft thus confirms the correlation referred to above, yet the role of hypnosis as a treatment modality for DID continues to be questioned. In the article, Kluft reviews the role hypnotically facilitated techniques can play and demonstrates the application of several of these techniques in the treatment of a DID patient. He concludes that therapists dealing with DID and Dissociative Disorder Not Otherwise Specified (DDNOS) should benefit from acquiring a general knowledge of hypnosis as well as expertise in the use of hypnosis in the treatment of dissociative disorders.

Although much has been written internationally about the use of early anecdotes in conventional counselling (Savickas, 2009; 2011), little has been written about their use in career counselling. Likewise, very little has been written about the crosswalk between the use of early anecdotes and the use of hypnotherapy in counselling. In the second contribution in the hypnosis section, Using 'informal' hypnotherapy in career counselling: blending Savickas and Erickson to 'free the angel', Jacobus Maree (2012) discusses this hiatus. A case study is presented in which the three anecdotes technique was used to enhance the career construction interviewing process during career construction counselling. The author concludes that the career construction interview (in combination with the three anecdotes technique) together with the use of basic Ericksonian strategies offers psychologists a promising way of administering informal hypnotherapy as well as career counselling. Given that all health profession and related practitioners routinely use informal hypnotherapeutic strategies and techniques to influence people, often without being aware of actually doing so, and that career counsellors, irrespective of whether they are trained hypnotherapists or not, implement strategies normally associated with Ericksonian hypnotherapy, this article warrants the attention of both groups of practitioners.

Large numbers of South African children suffer trauma on a daily basis. Sadly, the vast majority of these unfortunate youngsters are left to deal with the pain and confusion resulting from trauma with little if any help. Dissociative behaviour is often the outcome. In the third article in this section, The experiences of educational psychologists who utilise ego-state therapy to address dissociation in adolescents, Jenny da Silva and Elzette $\operatorname{Fritz}(2012)$ discuss this issue. The authors contend that although ego-state therapy is considered an effective therapeutic technique for dealing with dissociation, few studies by (educational) psychologists, who utilise this therapy with adolescents presenting 
with dissociation, are available. This article describes a study on educational psychologists' experiences of the process followed in ego-state therapy and elaborates on its appropriateness for adolescents experiencing dissociation.

In the fourth contribution in this section, "I DON'T REMEMBER DYING". A case study of the resolution of a Chronic Pain Syndrome utilising medical hypnoanalysis, Trevor Modlin (2012) argues that although chronic pain syndromes pose major challenges to clinicians, advances in epigenetics and analytical hypnotherapy facilitate understanding of how these syndromes develop and offer a means of bringing relief. Many chronic pain-related syndromes are based on faulty subconscious belief systems that result from early life imprints relating to spiritual issues. The author discusses the usefulness of medical hypnoanalysis with reference to a successful case history that demonstrates the role of some of the underlying dynamics of such analysis.

Clients often lament their inability to deal with and alter dysfunctional and repetitive patterns of behaviour in their lives. In the fifth contribution to this guest issue, Snow White and the curse of the Wicked Witch: The poisoned apple, the deep sleep and the awakening kiss, Ian Opperman and Elsabe Roets (2012) propose the Creation and Manifestation of Reality theory — which deals with the impact of perceived traumatic experiences that occur mainly in childhood - as a possible theoretical-conceptual framework to explain why many people re-enact dysfunctional patterns and attract dysfunctional relationships. The fairy tale of Snow White is used to illustrate the theory. The authors present three case studies to demonstrate how their theory could be applied successfully in hypnotherapy by theorists and practitioners alike.

Emotional and physical suffering, bullying and trauma are experienced by millions of people on a daily basis. Normal trauma-induced reactions to abnormal situations and symptoms of trauma are, tragically, often pathologized. The medical model is often used to diagnose traumatised clients as patients with (severe) pathology requiring symptomatic treatment (JOS, 2002). In the sixth contribution, Introducing SHIP ${ }^{\circledR}$ as a psychotherapeutic model to access the body memory of traumatised clients: depathologising expressions of trauma, Johan Steenkamp, Magiel van der Walt, Elna Schoeman-Steenkamp and Irene Strydom (2012) destigmatize the normal expressions and reactions of people's psycho-biodynamic systems to trauma. The SHIP ${ }^{\circledR}$ perspective on trauma is contextualised and serves as a contribution to the body of knowledge on positive psychology.

It is generally accepted that hypnotherapy can be used effectively to treat a wide variety of psychological disorders (Alladin \& Alibhai, 2007; Craig \& Quigley, 2010; Hammond, 2010; Schnur, Kafer, Marcus, \& Montgomery, 2008; Stewart, 2005). Maree (2010, p. 354) suggests that hypnotherapy also "offers a distinctive opportunity for enabling people to experience well-being, happiness, comfort, and fulfilment". In the seventh contribution to the section on hypnosis, Enhancing lives: A positive psychology agenda for hypnotherapy, Tharina Guse (2012), too, contends that hypnotherapy is not only an established treatment modality for psychological distress but can also promote wellbeing. Against the background of the limited literature on integrating positive psychology principles in hypnotherapeutic practice, this article elucidates the synergy between hypnotherapy and positive psychology by reviewing existing practices and research findings. The author offers suggestions for integrating positive psychology into hypnotherapeutic strategies and makes recommendations for further research. She highlights the importance of investigating the effectiveness of such strategies - informed by positive psychology in advancing the theory and practice of hypnotherapy in the $21 \mathrm{st}$ century - in the South African context and supports research methodologies that can provide insight into the unfolding of individual therapeutic change as well as the subjective experience of clients and therapists.

\section{Non-research-based contribution: opinion piece}

In the last of the hypnosis special issue contributions, Considering channelling and transpersonal phenomena from a quantum physics and developmental perspective, Jennifer Welch (2012) first 
considers the phenomenon of channelling and other transpersonal experiences and concepts in the light of recent research on aspects of quantum physics and then discusses research into the possibility that the human capacity for transpersonal experience may be understood from a developmental perspective.

The second batch of articles covers issues of a general nature.

\section{General issues}

Poverty in Africa is a multifaceted psycho-social phenomenon experienced particularly in family contexts. How the poorest families deal with poverty indicates their resilience. In the first article in this section (an international contribution), Psychological undertones of family poverty in rural communities in Cameroon: Resilience and coping strategies, Therese Tchombe, Almon Shumba, Joseph Lah Lo-oh, Théogène-Octave Gakuba, Martina Zinkeng and Teku Tanyi Teku (2012) employ a qualitative mode of inquiry to investigate the impact of poverty and family resilience strategies for dealing with poverty among the Bakweri of Bonavada villages in Cameroon. The authors conclude that the effects of family poverty are complex and that families depend largely on their natural resilience and socio-cultural context to cope with poverty.

Maria Marchetti-Mercer (2012), in the second contribution in this section, Is it just about the crime? A psychological perspective on South African emigration, also uses a qualitative research design to investigate the experiences of 10 South Africans prior to their emigration. The author finds that the socio-psychological context, within which the decision to emigrate is taken, is complex, involving several interlinked factors. She points out that emigration affects the people leaving as well as those left behind. Despite their awareness of the effect of their departure on significant others, emigrants have to cut themselves off psychologically from these significant others and separate themselves socially from the home country. The author emphasises the importance of adequate psychological and practical preparation prior to emigration and the necessity of considering the needs of any elderly people left behind.

Despite the new emphasis on the development of instruments to assess positive mental health and well-being, or HRQoL, a lack of and strong need for appropriate measures characterises this field (Hu, Stewart-Brown, Twigg, \& Weich, 2007; Robitail et al., 2006) in respect of child and adolescent populations locally and internationally. Naiema Taliep and Maria Florence (2012), in their article Evaluating the construct validity of the KIDSCREEN-52 quality of life questionnaire in a South African context, describe the circumstances that led to the use of the KIDSCREEN-52 questionnaire (developed and standardised in Europe) in South Africa. Using a large dataset $(N=565)$ as the initial step in the validation of the KIDSCREEN-52 for South African use, this study examined the KIDSCREEN-52's factor structure through exploratory factor analysis and determined the internal consistency reliability of each of the scales using Cronbach's alpha. Ten factors were extracted as identified by previous studies but with some deviation in the loadings of the last three factors. The authors stress the importance of ensuring that assessment instruments of the kind described here are reliable and valid for use in particular populations. Assessment instruments that claim to measure HRQoL while actually measuring something else can lead to distorted interpretations of the results, invalidate research using the instruments and have grave implications for those being assessed.

The next section deals with violent behaviour-related issues.

\section{Violent behaviour-related issues}

In the first article in this section, Patterns of physical assaults and the state of healthcare systems in South African communities, Peter Njuho and Alicia Davids (2012) discuss the results of a national population-based household survey on HIV prevalence, incidence, behaviour and communication in 
South Africa in 2008, by the Human Sciences Research Council (HSRC), and recommend the formulation of specific interventions to deal with violence issues in society as well as inequality and cultural relations. The authors also recommend the design and implementation of interventions that strengthen health care systems, that ensure a steady supply of medical products and that create a more effective delivery system.

In the last article in this issue, Entering the abyss: countertransference when working with torturers, Elaine Bing and Frederik Snyders (2012) explore countertransference themes that develop in therapeutic and research relationships with torturers and discuss ways of dealing with countertransference in relation to perpetrators.

Readers are once again invited to comment on the different authors' treatment of the topics raised in this issue. Let us know whether you think the topics (those pertaining to hypnotherapy as well as those of a more general nature) are relevant to 21 st century psychology. You are also encouraged to submit manuscripts that address gaps you have noticed in (South) African and other psychological research.

I wish to thank the SAJP's core editorial staff for their exceptional support and Mr Tim Steward for his editing of this editorial.

Enjoy reading this issue of the SAJP.

\section{Kobus Maree}

\section{REFERENCES}

Alladin, A., \& Alibhai, A. (2007). Cognitive hypnotherapy for depression: An empirical investigation. International Journal of Clinical and Experimental Hypnosis, 55, 147-166.

Allport, G. W. (1937). Personality: A psychological interpretation. New York, NY: Henry Holt \& Company.

Bing, E., \& Snyders, F. J. A. (2012). Entering the abyss: Countertransference when working with torturers. South African Journal of Psychology, 42, 282-289.

Craig, O.F. \& Quigley, E.M.M. (2010). Current and emerging therapies for the management of functional gastrointestinal disorders. Therapeutic Advances in Chronic Disease, 2, 87-99.

da Silva, J., \& Fritz, E.(2012). The experiences of educational psychologists who utilise ego-state therapy to address dissociation in adolescents. South African Journal of Psychology, 42, 169-181.

Guse, T. (2012). Enhancing lives: A positive psychology agenda for hypnotherapy. South African Journal of Psychology, 42, 214-223.

Hammond, D.C. (2010). Hypnosis in the treatment of anxiety-and- stress-related disorders. Expert Reviews of Neurotherapeutics, 10, 263-273.

Holland, J. H. (1996). Integrating career theory and practice. In Savickas, M.L., \& Walsh, W.B. (eds.), Handbook of career counselling theory and practice (pp. 1-10). Palo Alto, CA: Davies-Black Publishing.

Hu, Y., Stewart-Brown, S., Twigg, L., \& Weich, S. (2007). 'Can the 12-item General Health Questionnaire be used to measure positive mental health?' Psychological Medicine, 37, 1005-1013. doi: $10.1017 / \mathrm{S} 0033291707009993$

JOS. (2002). SHIP ${ }^{\circ}$. (Spontaneous Healing Intrasystemic Process): The age-old art of facilitating healing (14th impression). Pretoria: JOS.

Kluft, R. P. (2012). Hypnosis in the treatment of Dissociative Identity Disorder and Allied States: an overview and case study. South African Journal of Psychology, 42, 146-155.

Marchetti-Mercer, M. C. (2012). Is it just about the crime? A psychological perspective on South African emigration. South African Journal of Psychology, 42, 243-254.

Maree, J. G. (2010). Call for papers: Guest issue of South African Journal of Psychology. South African Journal of Psychology, 40, 364.

Maree, J. G. (2012). Using 'informal' hypnotherapy in career counselling: blending Savickas and Erickson to 'free the angel'. South African Journal of Psychology, 42, 156-168.

Maree, J. G., \& Molepo, J. M. (2007). Facilitating postmodern career counselling in the Limpopo Province 
of South Africa: A rocky ride to hope. Australian Journal of Career Counselling, 16, 62-70.

Modlin, T. (2012). "I DON'T REMEMBER DYING". A case study of the resolution of a Chronic Pain Syndrome utilising medical hypnoanalysis. South African Journal of Psychology, 42, 182-190.

Njuho, P., \& Davids, A. (2012). Patterns of physical assaults and the state of healthcare systems in South African communities. South African Journal of Psychology, 42, 270-281.

Opperman, M. C., \& Roets, H. E. (2012). Snow white and the curse of the wicked witch: the poisoned apple, the deep sleep and the awakening kiss. South African Journal of Psychology, 42, 191-201.

Phares, E. J. (1992). Clinical psychology: Concepts, methods and profession. Pacific Grove, NY: Brooks/Cole Publishing Company.

Robitail, S., Simeoni, M., Erhart, M., Ravens-Sieberer, U., Bruil, J., Auquier, P., \& The European Kidscreen Group. (2006). Validation of the European proxy KIDSCREEN-52 pilot test health-related quality of life questionnaire: First results. Journal of Adolescent Health, 39, 596.e1- 596.e10. doi: $10.1016 /$ j.jadohealth

Savickas, M. L. (1993). Career counselling in the post-modern era. Journal of Cognitive Psychotherapy: An International Quarterly, 7, 205-215.

Savickas, M. L. (2006a). Counselling for career construction (facilitating the storied approach in (career) counselling: practical implementation). 15th Australian Career Counselling Conference. Sydney. 18 April 2006.

Savickas, M. L. (2006b). A vocational psychology for the global economy. Keynote presentation, APA. New Orleans. 8 July 2006.

Savickas, M. L. (2007). Internationalisation of counselling psychology: Constructing cross-national consensus and collaboration. Applied Psychology: An International Review, 5691, 182-188.

Savickas, M. L. (2009). The essentials of life design counselling. Invited public lecture, University of Pretoria, Pretoria. 21 April 2009.

Savickas, M. L. (2011a). Reshaping the story of career counselling. In J. G. Maree (ed.), Shaping the story - a guide to facilitate narrative counselling (pp. 1-3). Boston/Rotterdam: Sense Publisher.

Savickas, M. L. (2011b). Career counselling. Washington: American Psychological Association.

Schnur, J., \& Montgomery, G. (2008). Hypnosis as cognitive-behavioral therapy during breast cancer radiotherapy: A case report. American Journal of Clinical Hypnosis, 50, 209-215.

Schnur, J. B., Kafer, I., Marcus, C. \& Montgomery, G. H. (2008). Hypnosis to manage distress related to medical procedures: A meta-analysis. Contemporary Hypnosis, 21, 114-128.

Stead, G. B. \& Watson, M. B. (1999). The appropriateness of Super's career theory among black South Africans. South African Journal of Psychology, 28, 40-43.

Steenkamp, J. O., Van der Walt, M. J., Schoeman-Steenkamp, E. M., \& Strydom, I. (2012). Introducing SHIP ${ }^{\circledR}$ as a psychotherapeutic model to access the body memory of traumatised clients: depathologising expressions of trauma. South African Journal of Psychology, 42, 201-213.

Stewart, J. H. (2005).Hypnosis in contemporary medicine. Mayo Clinic Proceedings, 80, 511-524.

Taliep, N., \& Florence, M. (2012). Evaluating the construct validity of the KIDSCREEN-52 Quality of Life questionnaire within a South African context. South African Journal of Psychology, 42, 255-269.

Tchombe, T. M. S., Shumba, A., Lo-oh, J. L., Gakuba, T., Zinkeng, M., \& Teku, T. T. (2012). Psychological undertones of family poverty in rural communities in Cameroon: Resilience and coping strategies. South African Journal of Psychology, 42, 232-242.

Welch, J. M. J. (2012). Considering channelling and transpersonal phenomena from a quantum physics and developmental perspective. South African Journal of Psychology, 42, 224-231. 